\title{
Duas soluções conversacionais para a descrição de inferências pressuposicionais em enunciados de sentenças negativas e condicionais com o gatilho ganhar
}

\author{
Two conversational solutions for the description of presuppositional \\ inferences in negative and conditional utterances with the trigger to win
}

Marcos Goldnadel

Resumo

O artigo realiza o cotejo de duas propostas para lidar com a projeção de pressuposições associadas ao gatilho ganhar em enunciados de sentenças negativas e condicionais. Apresenta-se inicialmente o modelo de análise presente em Romoli (2015), que considera implicaturas escalares obrigatórias as pressuposições decorrentes do uso de gatilhos leves. Em seguida, apresenta-se um modelo de análise alternativo, de acordo com o qual pressuposições disparadas por gatilhos leves são inferências conversacionais decorrentes da consideração de estados epistêmicos motivados pela consideração da semântica dos gatilhos leves e pela consideração de inferências conversacionais associadas à forma de enunciados negativos e condicionais.

Palavras-chave: pressuposição; problema da projeção de pressuposições, problema do disparo de pressuposições.

\section{Abstract}

This article compares two proposals devised to cope with presuppositions related to the trigger win in utterances of negative and conditional sentences. First, it is presented the analysis found in Romoli (2015), which regards presuppositions of soft triggers as obligatory scalar implicatures. Next, it is presented an alternative model, according to which presuppositions triggered by soft triggers are conversational inferences produced by the consideration of epistemic states caused by the semantics of the soft triggers, as well by the consideration of conversational inferences related to the form of negative and conditional utterances.

Keywords: presupposition; projection problem of presuppositions; triggering problem.

* Universidade Federal do Rio Grande do Sul 
M. Goldnadel

Duas soluções conversacionais para a descrição de inferências pressuposicionais em enunciados de sentenças negativas e condicionais com o gatilho ganhar

\section{Introdução}

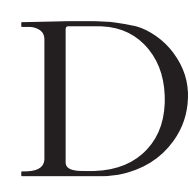
esde o início da década de setenta do século passado, quando o debate sobre pressuposição passou a ocorrer predominantemente no âmbito da Pragmática, a história dos estudos sobre o assunto pode ser dividida em dois grandes períodos no que diz respeito aos dois problemas centrais relativos ao tema: o problema da projeção e o problema da origem dos gatilhos. Até o final do século 20, a concepção predominante era a aquela segundo a qual os gatilhos pressuposicionais seriam o resultado de uma marcação convencional no léxico, cuja função precípua seria a de registrar uma relação de acarretamento entre o contexto e determinados conteúdos veiculados por enunciados'. Simons (2001), embora não tenha sido o primeiro trabalho acadêmico a sugerir a possibilidade de que inferências pressuposicionais sejam resultado de processos de natureza conversacional ${ }^{2}$, talvez tenha sido o primeiro a propor uma crítica mais articulada

1 Essa era a visão subjacente comum a teorias de índoles diversas, desde aquelas quase exclusivamente fundamentadas no pensamento griceano (Stalnaker (1973), Kartunnen (1973,1974), Gazdar (1979), Soames $(1979,1982)$, para citar apenas os mais conhecidos) até aquelas que propunham a utilização de aparato descritivos de modelos semântico-pragmáticos (HEIM, 2002; VAN DER SANDT, 1982; GEURTS, 1999).

2 A própria autora refere, na introdução do artigo, Stalnaker (1974) e Chierchia e McConellGinett (1990). O primeiro, trabalho fundador do debate sobre a questão pressuposicional, apresenta uma série de enunciados com inferências cuja projeção é apresentada como resultado de processos conversacionais de produção de sentido. Já o segundo limita-se a assumir a natureza conversacional de alguns tipos de pressuposição, tomando como base um dos exemplos
Revista Letras, Curitiba, UFPR, n. 96, pp.74-103, jul./dez. 2017. ISSN 2236-0999 (versão eletrônica) 
à alternativa convencionalista, a partir da formulação de duas objeções, uma de caráter descritivo, outra de caráter explanatório.

No campo da descrição, Simons observou que o caráter convencional dos gatilhos, embora ainda pudesse ser defendido em diversos casos em que a pressuposição deixava de se projetar - em teorias dinâmicas, como a FCS e a DRT, através do recurso descritivo da acomodação local, em teorias não dinâmicas como as propostas por Kartunnen $(1973,1974)$, Kartunnen e Peters (1979), Gazdar (1979) e Soames (1982), através de suspensão ou cancelamento -, não poderia ser sustentado na análise de exemplos como (1), extraído pela autora da tese de doutorado de Bart Geurts, publicada em 1994³.

(1) [Contexto: Um paciente, em sua primeira consulta médica, não para de roer um lápis.]

Médico: Eu estou notando que você fica roendo esse lápis. Você parou de fumar recentemente?

O problema que (1) coloca para as teorias convencionalistas é que o enunciado final contém um gatilho responsável por disparar idealmente a pressuposição de que o paciente fumava. Esse conteúdo não resulta efetivamente projetado, mas não há contexto local para acomodá-lo, o que constitui problema para as teorias dinâmicas. Tampouco seria possível encontrar, no quadro das descrições propostas por teorias não dinâmicas, conteúdo contextualmente acessível e contraditório com o conteúdo supostamente disparado pelo gatilho parar, já que, no exemplo, supõe-se uma primeira consulta, situação em que o médico não teria qualquer conhecimento sobre os hábitos do paciente. Contextos como esse, batizados por Simons como contextos de ignorância explícita, seriam, portanto, problemáticos para teorias convencionalistas, já que nenhum dos mecanismos propostos por essas teorias, acomodação ou cancelamento, poderiam ser supostos como explicação para a falha na projeção do conteúdo idealmente disparado pelo gatilho parar. Dito de outra forma, se realmente houvesse algum tipo de marcação convencional no léxico registrando a pressuposição, o que se esperaria seria a projeção, e não o desaparecimento da pressuposição.

Além de (1), Simons não teve dificuldade de encontrar outros exemplos em que a ignorância do falante quanto aos fatos impediria a projeção da pressuposição, como se observa em (2).

(2) A: Olha aquela menina ali chorando copiosamente. O que será que houve com ela?

B: Talvez ela tenha brigado com o namorado.

apresentados no artigo de Stalnaker. Nenhum dos dois, no entanto, dedica-se a elaborar uma crítica mais articulada à visão convencionalista.

3 No original: I notice that you keep chewing on your pencil. Have you recently stopped smoking? 
M. Goldnadel

Duas soluções conversacionais para a descrição

de inferências

pressuposicionais em enunciados

de sentenças

negativas e

condicionais com o gatilho ganhar

O adepto a uma teoria dinâmica poderia argumentar que modais de possibilidade criam subdomínios discursivos, encaixados na modalidade, nos quais a pressuposição poderia acomodar-se localmente. Nesse caso, o enunciado de B em (2) seria a expressão de algo como "Talvez ela tenha um namorado e tenha brigado com ele". O problema é que enunciados com modais de possibilidade integram a família de enunciados-teste para a identificação de gatilhos pressuposicionais. Admitir acomodação local em (2) seria, em princípio, o mesmo que banir enunciados modalizados dos testes para identificação de gatilhos, a não ser que se formulassem de modo muito preciso as condições nas quais modalizadores de possibilidade deixam de funcionar como teste, o que exigira, certamente, considerações relativas à máxima da relação. Em (2), por exemplo, parece claro que o enunciado do falante B responde a questão (3a), e não a qualquer uma das questões (3b), (3c) ou (3d).

(3a) O que está causando essa tristeza nela?

(3b) Ela brigou com o namorado?

(3c) Com que ela brigou?

(3d) Quem brigou com o namorado?

Note-se que apenas a questão (3a) constitui contexto para a suspensão da pressuposição. A questão (3b) já pressupõe a existência de um namorado. No caso de $(3 c)$ e (3d), um falante que cogitasse responder às questões com a afirmação da possibilidade de uma briga com um namorado e soubesse da inexistência desse namorado estaria violando a máxima da qualidade, já que não ter um namorado e ser possível brigar com um namorado são conteúdos evidentemente contraditórios. Tais análises, no entanto, já seriam um passo bastante consistente na direção de uma descrição puramente conversacional e não convencionalista, que muitos teóricos certamente não gostariam de dar.

A solução seria abandonar o modal de possibilidade como contexto teste para pressuposições. Mas aí seria necessário abandonar os demais testes (encaixamento em condicionais e perguntas), como fazem supor os exemplos (4) e (5).

(4) A: Olha aquela menina ali chorando copiosamente. O que será que houve com ela?

B: Se ela brigou com o namorado, tem motivos para estar assim.

(5) A: Olha aquela menina ali chorando copiosamente. O que será que houve com ela?

B: Será que ela brigou com o namorado?

Revista Letras,

Curitiba, UFPR, n. 96, pp. $74-103$, jul./dez. 2017. ISSN 2236-0999 (versão eletrônica) 
Ou seja, os contextos de ignorância explícita colocam os adeptos de teorias convencionalistas em um dilema: ou abrem mão dos testes classicamente utilizados para a identificação de gatilhos pressuposicionais, ou rumam na direção de descrições que incorporam mecanismos de natureza mais conversacional.

Adicionalmente aos problemas descritivos postos por casos em que um enunciado com o gatilho é proferido em um contexto de ignorância explícita, Simons chama a atenção ainda para problemas de caráter explanatório em teorias convencionalistas sobre pressuposições. $\mathrm{O}$ primeiro diz respeito à possibilidade de cancelamento de pressuposições, mecanismo reconhecido por muitas teorias ${ }^{4}$. O problema é que, em princípio, sentidos decorrentes de marcação convencional jamais poderiam ser cancelados por fenômenos conversacionais - como supõem, por exemplo, os modelos encontrados em Gazdar (1979) e Soames (1982) -, já que significados convencionalmente motivados teriam, por hipótese, precedência em processos de construção de sentido ${ }^{5}$.

Mas o problema explanatório mais grave apontado em Simons (2001) está relacionado à não destacabilidade de pressuposições, característica que compartilha com as implicaturas conversacionais. A consideração da propriedade da não destacabilidade como forte indicador de caráter conversacional de determinados processos de construção de sentido aparece em Grice (1989). De acordo com a lógica griceana, uma inferência que não se vê afetada pela substituição de sinônimos não deve ter origem convencional, já que parece depender do sentido semântico do enunciado, e não de alguma marcação idiossincrática presente em algum dos itens lexicais usados na sentença. Seria de se esperar, então, que, sendo os gatilhos pressuposicionais marcados convencionalmente para algum valor pragmático (como o são, por exemplo, certas conjunções), deveriam, então, contar com sinônimos não marcados convencionalmente para esse mesmo valor. Ocorre, no entanto, que todo esforço para encontrar termos semanticamente equivalentes e pragmaticamente distintos quanto ao aspecto pressuposicional tem sido infrutífero. Os sinônimos para o aspectual parar, por exemplo, cessar e interromper, carregam a mesma pressuposição. O mesmo ocorre com os iterativos: a par de de novo, o advérbio novamente e a expressão adverbial mais uma vez carregam a mesma pressuposição. Essa impossibilidade de encontrar sinônimos pressuposicionalmente distintos constitui evidência para o caráter conversacional de pressuposições ${ }^{6}$.

Abusch (2002), considerando os contextos de ignorância explícita identificados em Simons (2001) e as diferenças de possibilidade de cancelamentos 4 As teorias dinâmicas, que realizam suas descrições com base na ideia de satisfação de pressuposições, escapam a esse tipo de crítica, uma vez que, para elas, a pressuposição jamais é cancelada, mas apenas satisfeita localmente.

5 Essa é uma das razões para Kadmonn (2001) preferir o modelo de análise proposto por Kartunnen ao de Gazdar. Para a autora, as teorias dinâmicas seriam herdeiras da suposição, encontrada em Kartunnen (1974), de que não há projeção de pressuposições, mas sim satisfação, que pode ser global ou local. Para a autora, portanto, as teorias da satisfação são preferíveis com base em um critério de adequação explanatória.

6 O leitor interessado na utilidade dos testes para a determinação da natureza de fenômenos de sentido encontra uma extensa discussão em Oliveira (2015). 
M. Goldnadel Duas soluções conversacionais para a descrição de inferências pressuposicionais em enunciados de sentenças negativas e condicionais com o gatilho ganhar entre tipos de gatilhos, propõe uma divisão dos gatilhos entre gatilhos leves (soft triggers) e gatilhos pesados (hard triggers). Para ela, os gatilhos pesados seriam casos de pressuposição semântica, enquanto os leves seriam casos de pressuposição pragmática. A distinção visível para a determinação da natureza do gatilho seria a possibilidade de cancelamento. Gatilhos pesados não poderiam ser cancelados (como as clivadas e o item lexical também), enquanto gatilhos leves seriam suscetíveis a cancelamentos em contextos específicos. No artigo, a autora propõe uma descrição para a projeção das pressuposições associadas ao factivo saber e ao aspectual parar. Sua solução consiste em estipular que um gatilho leve pressupõe a verdade da disjunção de um conjunto de alternativas lexicalmente relacionadas. Um enunciado como (6), por exemplo, pressupõe a disjunção em (7). É a verdade dessa disjunção que acarreta a pressuposição do enunciado, em (8).

(6) Paulo não parou de fumar.

(7) Paulo parou de fumar $\vee$ Paulo continuou fumando.

(8) Paulo fumava.

Embora a solução de Abusch nada tenha de conversacional ${ }^{7}$, sua divisão entre gatilhos leves e pesados passou a figurar em uma série de trabalhos posteriores, dispostos a abandonar dois pressupostos teóricos profundamente arraigados (e intimamente relacionados) entre os que debatiam pressuposições no campo da Pragmática: a convencionalidade dos gatilhos e o próprio caráter da inferência a eles associada. Chemla (2008, 2009) e Romoli (2011, 2012, 2015) não só passaram a descrever pressuposições a partir de considerações de caráter conversacional, mas também abandonaram a ideia de que os gatilhos constituiriam uma espécie de registro formal sobre a forma do contexto que serve de base para as trocas conversacionais ${ }^{8}$.

Uma característica comum aos autores que participam desse segundo período histórico no campo dos estudos pressuposicionais é a de aproximar pressuposições (disparadas por gatilhos leves) a implicaturas de quantidade escalares, principalmente no que diz respeito aos mecanismos descritivos para lidar com o problema da projeção. As semelhanças entre implicaturas escalares e pressuposições quanto à projeção de conteúdos passaram a sugerir a possibilidade de um tratamento unificado para os dois fenômenos. Além disso, a ideia, originalmente encontrada em Abusch, de associar pressuposições a conjuntos de alternativas, reforçou a possibilidade de relacionar os fenômenos, já que as escalas de quantidade também são conjuntos de alternativas lexicais. Esse movimento desejável na direção de tratamentos não convencionalistas para um fenômeno com

7 A autora admite que, embora sua proposta seja de natureza pragmática, as diferentes alternativas são lexicalmente estipuladas.

8 Na verdade, a posição de Chemla é mais complexa. Em Chemla (2009), o autor cogita admitir o caráter de common ground para pressuposições, mas defende, em seguida, a ideia de que as inferências associadas a gatilhos sejam apenas conteúdo veiculado como background.
Revista Letras,

Curitiba, UfPr,

n. 96, pp.74-103,

jul./dez. 2017.

ISSN 2236-0999

(versão eletrônica) 
muitas das marcas registradas de fenômenos conversacionais (calculabilidade, cancelabilidade, não destacabilidade) tem se caracterizado, no entanto, pelo apelo a uma série de estipulações, necessárias para garantir descrições adequadas das inferências efetivamente produzidas a partir do uso de gatilhos presusposicionais nos mais diversos contextos.

Este artigo avalia o alcance e os limites para a descrição de pressuposições associadas ao gatilho ganhar em enunciados negativos e condicionais de uma das alternativas teóricas mais recentes para lidar com a questão pressuposicional nessa nova perspectiva conversacional, aquela defendida por Jacopo Romoli em uma série de trabalhos (Romoli 2011, 2012, 2015). Adicionalmente, apresenta uma solução alternativa, também de caráter conversacional, que supera alguns problemas encontrados no modelo de análise proposto por Romoli. O artigo é organizado da seguinte forma: na seção 1, apresenta-se o modelo proposto por Romoli, na seção 2, apresenta-se uma solução descritiva distinta, segundo a qual pressuposições são inferências conversacionais distintas de implicaturas.

\section{O modelo em Romoli (2015)}

Jacopo Romoli destaca-se, atualmente, como um dos pesquisadores mais produtivos no campo da discussão sobre pressuposições. Romoli (2015) pretende colaborar para a descrição de projeção de pressuposições em sentenças quantificadas. Para tanto, retoma, com algumas correções, a proposta presente em Romoli (2011). No artigo de 2015, o autor assenta os fundamentos necessários a uma descrição de inferências associadas a gatilhos pressuposicionais em enunciados negativos, interrogativos e condicionais, contextos centrais na discussão da projeção de pressuposições. No que se segue, apresentam-se os fundamentos da análise por ele proposta para sentenças negativas e condicionais.

\subsection{Pressuposições como implicaturas de quantidade escalares em enunciados de sentenças simples negativas}

Romoli (2015) estabelece um paralelo muito claro entre pressuposições e implicaturas escalares. Para o autor, assim como (9), (10) - em que o membro mais forte é um gatilho pressuposicional - também constitui uma escala.

(9) <Todo, Algum>

(10) <Ganhar, Participar>

Ambas as escalas estão constituídas a partir do mesmo princípio, a relação de acarretamento entre o membro mais forte e o mais fraco. Sendo assim, a escala em (10), assim como a escala em (9), está sujeita à mesma lei lógica da contraposição, que permite derivar as escalas (11) e (12). 
M. Goldnadel

Duas soluções conversacionais para a descrição de inferências pressuposicionais em enunciados de sentenças negativas e condicionais com o gatilho ganhar
(11) <Nenhum, algum não>

(12) <não participou, não ganhou>

Seriam justamente essas escalas as responsáveis pelas implicaturas (13b) e (14b) associadas a (13a) e (14a).

(13a) Alguns alunos não compareceram.

(13b) Alguns alunos compareceram.

(14a) Paulo não ganhou a corrida.

(14b) Paulo participou da corrida.

Adotando essa perspectiva, Romoli é obrigado a admitir, no entanto, uma diferença de comportamento entre os dois conjuntos de alternativas. Enquanto o conjunto \{todo, algum\} comporta-se de modo simétrico quanto à produção de inferências, o conjunto \{ganhar, participar\} apresenta uma assimetria, já que (15a) implica (15b), mas (16a) não implica (16b).

(15a) Alguns alunos compareceram.

(15b) Alguns alunos não compareceram.

(16a) Paulo participou da corrida.

(16b) Paulo não ganhou a corrida.

A diferença entre frases como (15a) e (16a) exige a primeira estipulação da teoria proposta por Romoli: diferentemente de ganhar, participar não tem alternativa.

Admitindo essa diferença, Romoli assume (em consonância com Chemla (2009)), a par da semântica dos gatilhos, um conjunto de alternativas responsáveis pela derivação de implicaturas9. Em (17) são apresentadas as formalizações encontradas em Romoli (2015) para a semântica dos gatilhos ganhar e parar, e para as alternativas a eles relacionadas, respectivamente ${ }^{10}$.

(17a) $[[$ ganhar $]]=\lambda x[$ ganhar $(\mathrm{x})]$

(17b) Alt $(17 \mathrm{a})=\{\lambda \mathrm{x}[\operatorname{ganhar}(\mathrm{x})], \lambda \mathrm{x}[\operatorname{participar}(\mathrm{x})]\}$

(17c) $[[$ parar $]]=\lambda P \lambda_{x}[\operatorname{parar}(x, P)]$

(17d) Alt $(17 \mathrm{c})=\{\lambda \mathrm{P} \lambda \mathrm{x}[\operatorname{parar}(\mathrm{x}, \mathrm{P})], \lambda \mathrm{P} \lambda \mathrm{x}[\operatorname{costumava}(\mathrm{x}, \mathrm{P})]\}$
Revista Letras,

Curitiba, UFPR,

n. 96, pp.74-103,

jul./dez. 2017. ISSN 2236-0999

(versão eletrônica)
9 Para ele, pressuposições são implicaturas escalares obrigatórias.

10 As formalizações em (17b) e (17d) são descrições das alternativas pragmáticas de (17a) e (17c). Em Romoli (2012), sua tese de doutorado, o autor admite que o problema da origem das pressuposições redimensiona-se, na perspectiva que adota, como o problema da origem das escalas propostas para a descrição da projeção. Em sua reflexão, apenas tangencia a questão acerca das operações efetivamente envolvidas na produção de escalas a partir do conteúdo semântico dos gatilhos. 
Sendo assim, um enunciado como (18a) apresenta as alternativas em (18b), assim como (19a) tem as alternativas em (19b).

(18a) Paulo parou de fumar.

(18b) \{Parou (p, fumar), Costumava (p, fumar)\}

(19a) Paulo não parou de fumar.

(19b) $\{\neg$ Costumava (p, fumar), $\neg$ Parou (p, fumar), $\}$

Tanto (18a) quanto (19a) permitem inferir que Paulo fumava. A diferença nos dois casos é o tipo de inferência: em (18) é um acarretamento, em (19), uma implicatura.

Contrariamente ao que sugere a exposição até aqui realizada, a proposta de Romoli não comunga de todas as conviç̧ões subjacentes aos modelos pragmáticos de forte inspiração griceana. Isso porque, para ele, a operação de negação de um elemento mais forte na escala, responsável pela implicatura, já tem início no módulo sintático através da ação de um operador de exaustificaçãa ${ }^{11}$. Ou seja, apesar da motivação para a consideração de escalas de informatividade ser fortemente conversacional, o modelo proposto assume - aqui mais uma estipulação - ser a presença de um operador de exaustificação no módulo sintático o responsável pelo acionamento das operações de exclusão de alternativas mais fortes de escalas. As razões para esse tipo de escolha são diversas, e a exiguidade deste espaço não permite maior detalhamento a esse respeito ${ }^{12}$. Basta, por ora, registrar que a ação desse operador de exaustificação na sintaxe permitiria a descrição de cancelamentos das inferências associadas a gatilhos a partir da suposição de que poderia ter escopos alternativos. A semântica proposta por Romoli para esse operador é apresentada em (20).

$$
[[\mathrm{EXH}]](\operatorname{Alt}(\mathrm{p}))(\mathrm{p})(\mathrm{w})=\mathrm{p}(\mathrm{w}) \wedge \forall \mathrm{q} \in \operatorname{Excl}(\mathrm{p}, \operatorname{Alt}(\mathrm{p}))[\neg \mathrm{q}(\mathrm{w})]
$$

O que (20) expressa é a semântica de um operador que toma como argumentos proposições, alternativas de proposições e mundos possíveis e entrega a proposição sobre a qual opera acrescida da negação de todas as alternativas passíveis de exclusão (excludable alternatives). Como nem todas as alternativas são passíveis de exclusão, Romoli as define como em (21).

\footnotetext{
11 Romoli assume a onipresença de um operador de exaustificação com escopo sobre qualquer sentença proferida, sempre pronto, portanto, a operar sobre eventuais escalas produzidas por itens lexicais. Nos casos clássicos de implicaturas escalares, entende que o operador entra em ação somente quando um traço de concordância $\sigma$, associado ao item escalar, recebe valor positivo em função de considerações relativas a relevância. Nos casos de pressuposições associadas ao uso de gatilhos leves, considera a operação de exaustificação obrigatória. Quando há suspensão da pressuposição, assume que, para evitar conflitos decorrentes de contradições, o operador de exaustificação passa a operar apenas localmente (solução similar à acomodação local das semânticas dinâmicas).

12 Um dos primeiros trabalhos a propor a ação de um operador de exaustificação para lidar com pressuposições é Fox (2007). Com esse mesmo recurso, Romoli (2012) propõe soluções para uma série de questões pragmáticas, como neg raising e free choice permission.
} 
M. Goldnadel

Duas soluções conversacionais para a descrição

de inferências

pressuposicionais

em enunciados

de sentenças

negativas e

condicionais com

o gatilho ganhar
(21) $\operatorname{Excl}(\mathrm{p}, \operatorname{Alt}(\mathrm{p}))=\{\mathrm{q} \in \operatorname{Alt}(\mathrm{p}): \mathrm{p} \not \subset \mathrm{q} \wedge \neg \exists \mathrm{r}[\mathrm{r} \in \operatorname{Alt}(\mathrm{p}) \wedge \neg \mathrm{q} \subseteq \mathrm{r}]\}$

(21) determina, primeiramente, que só podem ser excluídas (negadas) as alternativas da proposição expressa pelo enunciado que não sejam por ele acarretadas ${ }^{13}$. Uma segunda condição é a que impede que uma alternativa cuja negação acarrete outra alternativa seja excluível. Essa condição serve para eliminar das alternativas passíveis de exclusão aquelas que, ao serem excluídas impediriam a exclusão de outras, uma vez que essa exclusão produziria uma contradição. A seguir, a descrição do processo de produção da inferência associada ao enunciado (22) ilustra a ação do mecanismo proposto por Romoli ${ }^{14}$.

(22) João ganhou a corrida.

O enunciado, por conter o elemento escalar ganhar, aciona o conjunto de alternativas em (23).

\section{(23) $\{$ ganhou $(j), \operatorname{participou}(j)\}$}

Esse é o caso mais simples, porque a pressuposição é, na verdade, um acarretamento da proposição expressa por (22). De qualquer modo, o mecanismo proposto por Romoli impede que se exclua a segunda alternativa (participou(j)), já que, de acordo com a primeira cláusula de (21), só são excluíveis alternativas que não sejam acarretadas pela proposição expressa pelo próprio enunciado. Sendo assim participou(j) não constitui uma alternativa passível de exclusão, não podendo, portanto, sofrer a ação do operador de exaustificação. Da mesma forma, a alternativa ganhou(j) não é passível de exclusão, já que também é acarretada pela proposição original (toda proposição acarreta a si mesma). Sendo assim, a ação do exaustificador tem o resultado expresso em (24).

(24) $[[\mathrm{EXH}]][\operatorname{ganhou}(\mathrm{j})]=\operatorname{ganhou}(\mathrm{j})$

O caso mais interessante é o da negação, em (25).

(25) João não ganhou.

As alternativas de (25) estão em (26).

(26) $\quad \operatorname{Alt}(25)=\{\neg \operatorname{ganhou}(\mathrm{j}), \neg \operatorname{participou}(\mathrm{j})\}$

13 Essa condição é necessária porque, evidentemente, a negação (realizada no processo de exclusão promovido pelo operador EXH) de uma alternativa acarretada pela proposição expressa pelo enunciado produziria uma contradição.

14 Esta é a tradução para o português do exemplo apresentado pelo autor.
Revista Letras,

Curitiba, UFPR,

n. 96, pp.74-103,

jul./dez. 2017. ISSN 2236-0999

(versão eletrônica) 
Primeiramente, é preciso verificar se, de acordo com (21), a alternativa $\neg$ participou(j) pode ser exaustificada, ou seja, se pode ser negada. A primeira condição estabelecida em (21) é satisfeita, já que a alternativa expressa pelo próprio enunciado não a acarreta (ou seja, não ganhar não acarreta não participar). A segunda condição também é satisfeita, já que não há outra alternativa que seja acarretada pela negação de $\neg$ participou(j) (ou seja participou(j)). Sendo assim, a alternativa $\neg$ participou(j) é passível de exclusão, podendo, portanto, submeter-se ao processo de exaustificação em (27).

(27) $[[\mathrm{EXH}]][\neg \operatorname{ganhou}(\mathrm{j})]=\neg \operatorname{ganhou}(\mathrm{j}) \wedge \neg \neg \operatorname{participou}(\mathrm{j})=\neg$ ganhou $(\mathrm{j})$ $\wedge \operatorname{participou}(\mathrm{j})$

Percebe-se que o modelo descritivo proposto por Romoli funciona de modo bastante preciso e adequado na descrição de pressuposições disparadas por gatilhos em enunciados negativos. Como, no entanto, em sua perspectiva, a ideia de gatilho pressuposicional resulta substituída pela de escala de informatividade associada a determinados itens lexicais (sobre a qual age o operador de exaustificação), seria de esperar que as predições realizadas por seu modelo se realizassem de igual forma em relação a qualquer enunciado afirmativo com elementos presentes nas mesmas escalas associadas a enunciados contendo os tradicionais gatilhos. Não é isso que ocorre, por exemplo, com o enunciado (28).

(28) João participou da corrida.

As alternativas de (28) são as mesmas do enunciado (22), reapresentadas em (29).

\section{(29) $\quad\{$ ganhou $(\mathrm{j}), \operatorname{participou}(\mathrm{j})\}$}

O problema agora é que, ao contrário do que ocorre com (22), a alternativa que se distingue do enunciado não é por ele acarretada - participar não acarreta ganhar -, sendo, portanto, de acordo com o filtro proposto em (21), excluível. Ou seja, o mecanismo proposto por Romoli prediz a produção da inferência (30) a partir de (28).

(30) João não ganhou a corrida.

A solução de Romoli para casos como esse é estipular que, embora participar seja uma alternativa de ganhar, ganhar não constitui alternativa de participar. Essa estipulação, como tal, serve apenas para ajustar a descrição, contrariando a ideia que parece animar a solução proposta, a de que determinadas inferências decorrem da consideração de que, em suas contribuições conversacionais, falantes buscam entregar a maior quantidade 
M. Goldnadel Duas soluções conversacionais para a descrição de inferências pressuposicionais em enunciados de sentenças negativas e condicionais com o gatilho ganhar

de informação possível. O autor não chega a admitir, mas com essa solução ad hoc, a convenção, antes atribuída aos gatilhos, retorna, agora de modo mais sutil, na forma de determinação de que itens lexicais são capazes de produzir escalas. Expulsa pela porta da frente, a convenção retorna pela porta dos fundos, acompanhada de outra, a que preconiza a presença de um operador invisível de exaustificação na sintaxe, responsável pela exclusão de apenas algumas das alternativas informacionalmente mais fortes. Romoli converte, portanto, problemas de natureza descritiva em problemas de natureza explanatória: como admitir para um fenômeno com características notadamente conversacionais, tantas convenções? O modelo, no entanto, mesmo com as estipulações que o caracterizam, não está livre de problemas descritivos relacionados à projeção de inferências associadas a gatilhos em proferimentos de sentenças condicionais, tema das próximas seções.

\subsection{Pressuposições como implicaturas de quantidade escalares em antecedentes de enunciados de sentenças condicionais}

O modelo encontrado em Romoli (2015) apresenta relativo sucesso descritivo quando aplicado a enunciados de sentenças condicionais, uma vez que faz predições adequadas apenas nos casos em que o gatilho aparece no antecedente do condicional. Nos casos em que o gatilho figura no consequente, o próprio autor admite que sua solução padece do problema da provisoriedade (cf. GEURTS, 1999). O enunciado com gatilho no antecedente analisado pelo autor é (28).

(31) Se Jane ganhou, ela está celebrando agora.

A análise de (31) encontrada em Romoli (2015) parte do pressuposto de que se trata de uma implicação material e de que sua forma proposicional, expressa em (32a), é equivalente à forma expressa em (32b).

(32a) $\mathrm{p} \rightarrow \mathrm{q}$

(32b) $\neg \mathrm{p} \vee \mathrm{q}$

Com base nessa equivalência, Romoli propõe que condicionais tenham as mesmas alternativas que seus equivalentes disjuntivos, conforme se vê em (33a) e (33b)

(33) $\quad$ Alt $(\mathrm{p} \rightarrow \mathrm{q})=\{\mathrm{p} \rightarrow \mathrm{q}, \neg \mathrm{p}, \mathrm{q}\}$

(33b) Alt $(\neg p \vee q)=\{\neg p \vee q, \neg p, q\}$

Revista Letras,

Curitiba, UFPR,

n. 96 , pp.74-103,

jul./dez. 2017.

ISSN 2236-0999

(versão eletrônica) 
Segundo esse critério, as alternativas de (31) deveriam ser as apresentadas em (34).

$$
\operatorname{Alt}(28)=\{\operatorname{ganhou}(j) \rightarrow \operatorname{celeb}(j), \neg \text { ganhou }(\mathrm{j}), \operatorname{celeb}(\mathrm{j})\}
$$

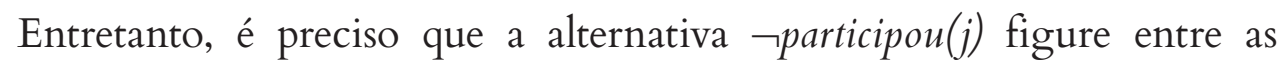
alternativas ${ }^{15}$ e, de fato, é isso que a condição (21) - repetida abaixo - pretende garantir.

$$
\text { (21) } \operatorname{Excl}(\mathrm{p}, \text { Alt }(\mathrm{p}))=\{\mathrm{q} \in \text { Alt }(\mathrm{p}): \mathrm{p} \not \subset \mathrm{q} \wedge \neg \exists \mathrm{r}[\mathrm{r} \in \text { Alt }(\mathrm{p}) \wedge \neg \mathrm{q} \subseteq \mathrm{r}]\}
$$

Note que, na condição (21), as metavariáveis 'p' e 'q' não remetem a antecedentes ou consequentes de possíveis condicionais, mas a proposições contendo alternativas lexicais cujo resultado não seja um acarretamento da proposição expressa pelo enunciado proferido. Sendo assim, (21) deve operar sobre um conjunto de alternativas lexicalmente determinadas, tendo em vista os itens lexicais de natureza escalar encontrados no enunciado em análise. Mas como são geradas essas alternativas a serem submetidas ao mecanismo (21), a fim de que, após essa submissão, sobrem apenas aquelas a serem exaustificadas na sintaxe? Esse passo, não explicitado nos trabalhos de Romoli, é proposto a seguir para sentenças condicionais.

$$
\begin{aligned}
& \text { Alt }(\mathrm{p} \rightarrow \mathrm{q})=\{\mathrm{p} \rightarrow \mathrm{q}, \neg \mathrm{p}, \mathrm{q},\} \cup\{\beta: \forall \alpha(\mathrm{p} \subset \alpha) \rightarrow(\beta=\neg \alpha)\} \cup\{\delta: \forall \gamma \forall \psi \\
& [(\mathrm{p} \subset \gamma) \&(\psi=\gamma \rightarrow \mathrm{q})] \rightarrow \delta=\psi\}
\end{aligned}
$$

O que (35) estipula é que o conjunto de alternativas lexicalmente produzidas (para, em seguida, sofrerem o processo de seleção (21), responsável por filtrar apenas aquelas alternativas que podem ser exaustificadas) a partir do proferimento de um enunciado condicional é composto pela proposição expressa pelo próprio enunciado, pela negação do antecedente, pela afirmação do consequente, pelo conjunto de proposições que se caracterizam por ser negações de acarretamentos do antecedente e, finalmente, pelo conjunto de proposições cuja forma é idêntica à do condicional proferido, com a única diferença de que o antecedente dessas proposições seja acarretado pelo antecedente do condicional original. Vale notar que todas as proposições produzidas de acordo com (35) acarretam a sentença condicional proferida no enunciado, obedecendo, portanto, ao desejo de Romoli de produzir como alternativas apenas as proposições informacionalmente tão fortes ou informacionalmente mais fortes que a expressa pelo enunciado proferido. O conjunto de proposições sugeridas como alternativas de (31) repetido abaixo - em Romoli (2015) é justamente aquele que resulta da aplicação de (35) ao enunciado. Esse conjunto, tal como sugerido pelo autor, está em (36).

15 Já que é ela que deverá ser negada pelo processo de exaustificação a fim de obter-se a inferência desejada. 
M. Goldnadel

Duas soluçôes conversacionais para a descrição

de inferências

pressuposicionais

em enunciados

de sentenças

negativas e

condicionais com

o gatilho ganhar
(31) Se Jane ganhou, ela está celebrando agora.

(36) $\operatorname{Alt}(31)=\{$ ganhou $(j) \rightarrow \operatorname{celeb}(j), \neg \operatorname{ganhou}(j), \operatorname{celeb}(\mathrm{j}), \neg$ participou $(\mathrm{j})$, $\operatorname{participou}(\mathrm{j}) \rightarrow \operatorname{celeb}(\mathrm{j})\}$

Deposse do conjunto de alternativastão ou maisfortesinformacionalmente, agora é possível aplicar o filtro (21) - repetido abaixo - para identificar quais das alternativas seguem para o processo sintático de exaustificação.

$$
\operatorname{Excl}(\mathrm{p}, \operatorname{Alt}(\mathrm{p}))=\{\mathrm{q} \in \operatorname{Alt}(\mathrm{p}): \mathrm{p} \not \subset \mathrm{q} \wedge \neg \exists \mathrm{r}[\mathrm{r} \in \operatorname{Alt}(\mathrm{p}) \wedge \neg \mathrm{q} \subseteq \mathrm{r}]\}
$$

A primeira condição de (21) - p $\not \subset \mathrm{q}-$ é responsável por eliminar apenas o primeiro elemento de possíveis alternativas em (33). O resultado dessa eliminação é o conjunto (37).

$$
\begin{aligned}
& \operatorname{Alt}(28)_{\text {parcial-excl }}=\{\neg \operatorname{ganhou}(\mathrm{j}), \operatorname{celeb}(\mathrm{j}), \neg \operatorname{participou}(\mathrm{j}), \operatorname{participou}(\mathrm{j}) \rightarrow \\
& \operatorname{celeb}(\mathrm{j})\}
\end{aligned}
$$

Feita a eliminação, falta submeter as alternativas restantesem (37) aosegundo critério de exclusão em (21). Segundo esse critério, é necessário eliminar todas as alternativas cuja negação acarrete alguma das outras alternativas. Comecemos pela primeira. A negação de $\neg$ ganhou(j) é ganhou(j). Esse resultado, em uma primeira verificação, parece não acarretar nenhuma das outras alternativas. É preciso notar, no entanto, que ganhou(j), quando considerado em conjunto com o condicional proferido pelo enunciador, acarreta celeb(j). Sendo assim, ganhou(j) acarreta outro elemento das alternativas, recomendando, portanto, retirada do conjunto de $\neg$ ganhou(j).

O próximo elemento do conjunto provisório de alternativas é celeb(j), cuja negação é $\neg$ celeb(j). Aqui, mais uma vez, a negação produzida não acarreta diretamente qualquer das demais alternativas. Entretanto, se considerarmos essa negação em conjunto com o condicional proferido pelo enunciador, derivamos inferencialmente $\neg$ ganhou(j), uma das alternativas inicialmente estabelecidas. Novamente, então, a alternativa deve ser eliminada em função do segundo critério em (21).

O elemento seguinte do conjunto (37) é $\neg$ participou(j). Sua negação é participou(j). Aqui, diferentemente dos casos anteriores, a negação resultante, além de não acarretar qualquer outro elemento do conjunto, considerada em conjunto com a proposição condicional expressa pelo enunciado proferido, não acarreta qualquer das demais alternativas. Sendo assim, a alternativa $\neg$ participou(j) resiste ao filtro (21) e qualifica-se como um dos elementos a serem sintaticamente exaustificados.
Revista Letras, Curitiba, UFPR, n. 96, pp.74-103, jul./dez. 2017. ISSN 2236-0999 (versão eletrônica) 
Por fim, a negação da alternativa participou(j) $\rightarrow$ celeb(j), a saber, $\neg[\operatorname{participou}(\mathrm{j}) \rightarrow \operatorname{celeb}(\mathrm{j})]$, assim como os dois primeiros elementos do conjunto de alternativas, também não passa pelo filtro (21), devendo ser eliminado. Para facilitar a verificação, basta considerar as equivalências dessa negação a seguir.

(38) $\quad \neg[\operatorname{participou}(\mathrm{j}) \rightarrow \operatorname{celeb}(\mathrm{j})]$

(39) $\quad \neg[\neg \operatorname{participou}(\mathrm{j}) \vee \operatorname{celeb}(\mathrm{j})]$

(40) $[\operatorname{participou}(\mathrm{j}) \wedge \neg \operatorname{celeb}(\mathrm{j})]$

Como se pode verificar, o segundo conjunto de (40), em combinação com o condicional proferido acarreta $\neg$ ganhou(j), o primeiro elemento do conjunto (37). Ao fim e ao cabo, o único elemento do conjunto inicial (36) que resiste ao filtro (21), constituindo, portanto, a única alternativa excluível (passível de ser negada pelo operador de exaustificação) é o que aparece em (41).

(41) $\quad \operatorname{Alt}(28)_{\text {excl }}=\{\neg \operatorname{participou}(j)\}$

Sendo assim, a exaustificação de (31) é apresentada em (42).

(42) $[[\mathrm{EXH}]][\operatorname{ganhou}(\mathrm{j}) \rightarrow \operatorname{celeb}(\mathrm{j})]=\operatorname{ganhou}(\mathrm{j}) \rightarrow \operatorname{celeb}(\mathrm{j}) \wedge \neg \neg$ participou $(\mathrm{j})$ $=\operatorname{ganhou}(\mathrm{j}) \rightarrow \operatorname{celeb}(\mathrm{j}) \wedge \operatorname{participou}(\mathrm{j})$

Percebe-se, portanto, que o mecanismo proposto por Romoli descreve adequadamente a inferência associada ao gatilho ganhar no condicional analisado.

\subsection{Pressuposições como implicaturas de quantidade escalares em consequentes de enunciados de sentenças condicionais: $o$ problema da provisoriedade}

Curiosamente, o sucesso descritivo de Romoli na descrição de enunciados negativos simples com gatilhos e de enunciados condicionais com gatilhos no antecedente não se repete em condicionais com gatilhos no consequente. Para perceber o problema enfrentado, considere o enunciado (43).

(43) Se João estava em forma, então ele ganhou a corrida.

O problema aqui é que as únicas alternativas produzidas pelo algoritmo (35), ou seja, as únicas proposições lexicalmente relacionadas que sejam tão ou mais fortes informacionalmente que (43) são as que figuram em (44). 
M. Goldnadel

Duas soluções conversacionais para a descrição

de inferências

pressuposicionais em enunciados

de sentenças

negativas e

condicionais com

o gatilho ganhar
(44) $\quad \operatorname{Alt}(43)=\{$ forma $(j) \rightarrow \operatorname{ganhou}(j), \neg$ forma $(j)$, ganhou(j) $\}$

Acontece que todas essas alternativas não resistem ao filtro (21), não sendo, portanto, excluíveis, de modo que a ação do operador de exaustificação, na sintaxe, resulta apenas no valor semântico da sentença, cf. (45).

(45) $[[\mathrm{EXH}]][$ forma $(\mathrm{j}) \rightarrow \operatorname{ganhou}(\mathrm{j})]=$ forma $(\mathrm{j}) \rightarrow \operatorname{ganhou}(\mathrm{j})$

O modelo de Romoli, no entanto, prevê um acarretamento que o autor prefere chamar de pressuposição provisória. De fato, (43) acarreta (46).

(46) Se João estava em forma, então ele participou a corrida.

(47) João participou a corrida

Romoli considera (46) uma pressuposição de (43), uma instância daquilo que Geurts (1999) chama de proviso problem ${ }^{16}$. O autor não chega a enfrentar esse problema, ou seja, não propõe qualquer mecanismo descritivo para derivar de (43) a inferência (47), a efetiva pressuposição do enunciado. Em vez disso, remete a outros autores que, segundo ele, oferecem tratamento adequado a esse tipo de problema.

\subsection{Problemas explanatórios com a proposta de Romoli}

Embora Romoli apresente-se como adepto de uma solução conversacional para lidar com pressuposições, é preciso reconhecer que, apesar da identificação que faz entre pressuposições e implicaturas conversacionais (implicaturas de quantidade escalares), sua proposta não pode ser considerada, de fato, muito distinta das soluções convencionalistas presentes na literatura. $\mathrm{O}$ abandono do caráter convencional dos gatilhos, movimento necessário em propostas que desejam enfrentar o problema explanatório do surgimento de pressuposições, exige ajustes significativos na forma de descrever o fenômeno (de lidar com o problema da projeção). São esses ajustes descritivos que representam o maior desafio para as abordagens conversacionalistas.

O primeiro passo de Romoli na direção de uma abordagem conversacionalista é abandonar a suposição de convencionalidade dos gatilhos leves, incluindo-os no grupo de lexemas responsáveis pela geração de implicaturas

16 No âmbito das teorias dinâmicas para descrever a projeção de pressuposições, o problema da provisoriedade não tem maiores consequências quando a pressuposição do consequente é acarretada pelo antecedente do condicional ou pela conjunção de alguma proposição parte do contexto com a proposição expressa pelo antecedente. O problema está nos casos em que o antecedente do condicional não colabora para a satisfação da pressuposição disparada no gatilho do consequente.
Revista Letras,

Curitiba, UFPR,

n. 96, pp.74-103,

jul./dez. 2017.

ISSN 2236-0999

(versão eletrônica) 
escalares. Esse movimento, embora intuitivamente motivado - de fato, escalas, em uma primeira aproximação, parecem responsáveis pela geração de inferências pressuposicionais -, conduz a resultados descritivos indesejáveis. Como se pode ver na seção 1.1, esses resultados obrigam Romoli a uma primeira estipulação: os itens que compõem as escalas responsáveis pela geração de pressuposições não são simétricos, de modo que, num determinado par, o elemento A pode ser a alternativa do elemento $\mathrm{B}$, mas o inverso pode não ser verdade. A pergunta que fica é a seguinte: de onde vem essa determinação de que certos itens do léxico não possuem alternativas, embora pertençam a escalas? Se um item de uma "escala pressuposicional" precisa ser marcado convencionalmente como ativo, não seria isso uma readmissão da convenção que se desejava expurgar com a adoção de uma teoria alternativa, conversacional?

O caráter convencional do modelo de Romoli, no entanto, não se restringe à estipulação de alternativas ativas em escalas. Um segundo recurso, o operador de exaustificação na sintaxe, mais do que admitir uma nova convenção, ameaça o caráter conversacional de fenômenos que, por boas razões, têm sido vistos como resultado de processos inferenciais pós-proposicionais (ou seja, processos que tomam a proposição expressa por um enunciado como premissa inicial, e não fragmentos de enunciados antes mesmo de seu processamento pragmático primário). Nesse aspecto, alinha-se com Chierchia (2012). Os problemas descritivos que uma tal suposição procura resolver não são pequenos, e o sucesso descritivo dos modelos que seguem essa tendência pode, em princípio, justificar sua adoção. O problema com a proposta de Romoli, no entanto, é que sua descrição da projeção de pressuposições em sentenças condicionais parece obrigá-lo a assumir, em determinado ponto de suas derivações, um ponto de vista oposto ao que anima propostas como a sua.

O leitor atento talvez tenha percebido, na seção 1.2 deste artigo, que, ao aplicar o filtro (21) a alternativas de escalas associadas a sentenças condicionais, para verificar se essas alternativas seriam passíveis de exclusão, foi necessário considerar essas alternativas em conjunto com a proposição expressa pela sentença proferida. Mais especificamente, foi analisado o enunciado (31), repetido abaixo, cujo proferimento geraria o conjunto de alternativas (36), também repetido.

(31) Se Jane ganhou, ela está celebrando agora.

(36) $\operatorname{Alt}(31)=\{$ ganhou(j) $\rightarrow \operatorname{celeb}(\mathrm{j}), \neg \operatorname{ganhou}(\mathrm{j}), \operatorname{celeb}(\mathrm{j}), \neg \operatorname{participou}(\mathrm{j})$, $\operatorname{participou}(\mathrm{j}) \rightarrow \operatorname{celeb}(\mathrm{j})\}$

Ao filtro (21), então, caberia verificar quais elementos de (36) seriam passíveis de exclusão. Para tanto, o filtro estabelece que uma alternativa só pode ser excluída (portanto, exaustificada) se sua negação não acarretar nenhuma das outras alternativas. Como vimos, de acordo com a simples aplicação do filtro, a segunda alternativa do conjunto $(\neg \operatorname{ganhou}(\mathrm{j}))$, não deveria, em princípio, ser 
M. Goldnadel

Duas soluções conversacionais para a descrição de inferências pressuposicionais em enunciados de sentenças negativas e condicionais com o gatilho ganhar filtrada - já que sua negação não entra em contradição com nenhuma das outras alternativas - ficando livre, portanto, para o processo de exaustificação, que produziria a sua negação, em (48).

\section{(48) ganhou(j)}

Ocorre que (48) não é uma inferência de (31). Ou seja, a simples consideração da ação do filtro (21) sobre o segundo elemento de (36) não produz o resultado intuitivamente desejável.

Para corrigir essa falha descritiva, naquele ponto da análise, foi, então, necessário dar um passo a mais na utilização do filtro, considerando que a seria a interação de (48) com a proposição expressa pelo próprio enunciado que acarretaria outro elemento da escala. De fato, a combinação de (31) com (48) produz a inferência (49) - por modus ponens. ${ }^{17}$

(49) celeb(j)

Agora sim, o filtro, tendo considerado o enunciado proferido, é capaz de produzir inferencialmente, a partir da consideração da alternativa $\neg$ ganhou(j), uma proposição que consiste em outro elemento do conjunto de alternativas (36) - expressa em (49) -, alcançando o resultado necessário para que a proposição $\neg$ ganhou(j) seja retirada do conjunto de alternativas passíveis de exclusão, o que, em última instância, impede a sua negação e a produção do indesejável resultado (48).

Embora, a solução de assumir que o filtro (21), em sua ação, deve tomar os um a um -, mas também a proposição expressa pelo enunciado, possa ser descritivamente adequada, ela coloca problemas sérios para Romoli no que diz respeito a suas opções explanatórias. A suposição de um operador de exaustificação na sintaxe deveria, em princípio, servir para dotar o modelo da capacidade de gerar resultados inferenciais em um nível subproposicional, antes mesmo da consideração da interpretação do enunciado como um todo. Em termos de processamento, a teoria deveria prever que o processo de exaustificação em um enunciado condicional com um gatilho no antecedente, por exemplo, já deveria ocorrer no momento do processamento desse antecedente. Não é isso que a descrição de um enunciado desse tipo a partir do mecanismo proposto por Romoli, apresentada integralmente na seção 1.2 deste artigo, revela. De acordo com esse mecanismo, é preciso supor que o filtro (21) também leva em consideração o enunciado já integralmente processado. O problema com esse tipo de suposição,

17 No artigo aqui resenhado, Romoli ignora esse problema. A seção 3.3.2 (Antecedents of conditionals) não se estende por mais que uma página, limitando-se a afirmar que a alternativa $\neg$ participou(j) candidata-se ao processo de exaustificação. Com isso, descreve a inferência desejada, mas exime-se de aplicar o mecanismo descritivo proposto a todas as alternativas

Revista Letras, supostas e de, nessa aplicação, enfrentar as questões aqui colocadas.

Curitiba, UFPR,

n. 96, pp.74-103,

jul./dez. 2017. ISSN 2236-0999

(versão eletrônica) 
no entanto, é que uma operação na sintaxe, que, por hipótese, age de modo cego sobre informações locais, deve acessar conteúdos cuja produção só é possível após a execução completa das operações sintáticas. De modo resumido, consiste em supor que a sintaxe depende da pragmática, que, por sua vez, depende da sintaxe. Salvo melhor juízo, a proposta do autor obriga a supor um modelo de gramática que peca por uma circularidade perigosa.

\section{Uma outra alternativa inferencial: semântica do gatilho, negação e máximas griceanas}

Esta seção é dedicada a apresentar uma solução alternativa para a descrição da projeção de pressuposições aplicada aos mesmos casos apresentados na seção 1 deste trabalho. Essa alternativa também considera pressuposições inferências pragmáticas, mas, contrariamente à hipótese de Romoli, não assimila os casos clássicos a implicaturas de qualquer natureza, embora leve em consideração a ação das máximas griceanas na descrição do processo de produção de inferências tradicionalmente consideradas pressuposições. Fundamental nesse modelo é a consideração de aspectos pragmáticos, como o monitoramento de inconsistências entre estados epistêmicos tornados manifestos pelo uso de enunciados. Fundamental também é a consideração da semântica dos gatilhos. Comecemos pela análise de semântica de gatilhos como ganhar.

Como se sabe, ganhar, no sentido de vencer, acarreta participar. Ou seja, não é possível ganhar sem participar. Esse é um acarretamento semântico. Pode haver alguma objeção a esse tipo de afirmação, mas há razões para supor que o evento de ganhar seja um subevento do evento de participar de uma competição, ocorrendo, necessariamente, no ponto temporal final do intervalo que compreende o evento de participação. Sendo assim, o evento de vitória assume sentido apenas como subevento de um evento mais amplo, que é o da participação. Dito de outra forma, a relação entre o evento de vitória e o evento de participação é a de meronímia. Como em toda a relação de meronímia, não é possível dar sentido à parte se não for possível dar sentido ao todo. Imaginese, por exemplo, a situação de uma maratona em que haja uma fita no ponto de chegada, que deverá ser rompida pelo vencedor. Numa situação como essa, um transeunte que tenha invadido a pista e passado através da fita rompendo-a não venceu a corrida. Isso porque não é o evento de romper a fita que caracteriza o evento de vitória. O evento de vitória está meronimicamente relacionado ao evento participar da corrida, cuja verificação só poderá ser positiva para todo

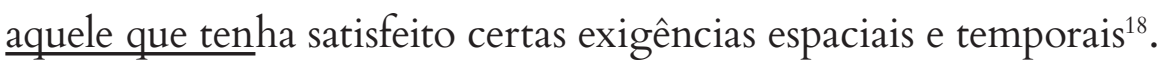

18 Um corredor que tenha percorrido a mesma distância em outro país em tempo menor que o corredor da maratona que tenha rompido a fita, por exemplo, não será considerado o vencedor da corrida. Tampouco um corredor que tenha percorrido o mesmo percurso em outro dia 
M. Goldnadel

Duas soluções conversacionais para a descrição de inferências pressuposicionais em enunciados de sentenças negativas e condicionais com o gatilho ganhar
Pelos motivos expostos, a partir deste ponto, passa-se a considerar que um enunciado como (50) acarreta semanticamente a conjunção (51).

(50) João ganhou a corrida.

(51) $\quad \operatorname{ganhou}(\mathrm{j}) \wedge \operatorname{participou}(\mathrm{j})$

No caso de uma sentença afirmativa, portanto, não há o que se possa considerar pressuposição, apenas acarretamento.

Como explicar, no entanto, a projeção do conteúdo do segundo conjunto de (50) - participou(j) - em sentenças negativas. Assume-se aqui que a negação tem escopo semântico amplo em sentenças com múltiplos acarretamentos. Sendo assim, a negação de (50), em (52), é semanticamente, o que se vê em (53) ${ }^{19}$.

(52) João não ganhou a corrida.

(53) $\neg[$ ganhou $(j) \wedge \operatorname{participou}(j)]$

Ocorre que a negação em (53), por ser de escopo amplo, é pouco informativa, já que é compatível com a negação de qualquer um dos conjuntos. A especificação de escopo, portanto, é uma operação pragmática. Mas como explicar que a operação default seja aquela em que a negação acaba por direcionarse para o primeiro conjunto de (53)?

A opção de considerar que a negação opera sobre os dois conjuntos, por exemplo, é pragmaticamente problemática. Como ganhar acarreta participar, se o falante quisesse dizer João não participou e não ganhou a corrida, teria sido mais breve se negasse apenas a sua participação. Uma outra alternativa, aquela segundo a qual a negação estaria operando apenas sobre o segundo conjunto, não seria possível, por levar a uma contradição, violando a máxima da qualidade. Como seria possível negar que João participou da corrida e, ao mesmo tempo, preservar a afirmação de uma vitória, já que a vitória acarreta a participação? Feitas essas considerações, resta apenas uma alternativa pragmática que não viola qualquer uma das máximas conversacionais griceanas, aquela em que a negação opera apenas sobre o primeiro conjunto de (53), o que resulta na leitura (pragmaticamente derivada) (54).

$$
\neg \operatorname{ganhou}(\mathrm{j}) \wedge \operatorname{participou}(\mathrm{j})
$$

De acordo com a perspectiva aqui adotada, (54) é uma inferência conversacional que decorre da especificação de escopo sobre a representação semântica (53). Não resulta, no entanto, da consideração de qualquer escala ou

terá vencido a corrida. Um evento, pelo menos nos moldes tradicionais, para ser considerado uma corrida precisa contar com mais de um participante, percorrendo o mesmo percurso, em intervalos de tempo iniciados no mesmo momento e associados pela relação de inclusão. 19 Nesse aspecto, o modelo aqui proposto está de acordo com o que se preconiza em Carston (1998).
Revista Letras,

Curitiba, UFPR,

n. 96, pp.74-103,

jul./dez. 2017.

ISSN 2236-0999

(versão eletrônica) 
conjunto de alternativas lexicais. O que se assume é que, assim como (51) é a representação semântica de (50), (53) é a representação semântica de (52). Não é necessário, portanto, apelar para nenhum mecanismo de geração de escalas. $\mathrm{O}$ que ocorre é que aquilo que a sentença afirmativa acarreta a sentença negativa implica através da ação de um a lógica conversacional que opera sobre o conteúdo literal de sentenças negativas como (52) - representado formalmente em (53).

Para compreender melhor a diferença desta abordagem para a de Romoli, basta considerar inferências similares produzidas a partir de outros acarretamentos presentes em sentenças como (50). Além de (51), (50) acarreta (55).

$$
\operatorname{ganhou}(\mathrm{j}) \wedge \exists(\mathrm{x})[\operatorname{ganhou}(\mathrm{x})]
$$

Ou seja, o enunciado (50) acarreta a si mesmo e a proposição de que alguém ganhou a corrida. Sua negação em (52) pode ser considerada semanticamente como a representação $(56)^{20}$.

\section{(56) $\neg[$ ganhou $(\mathrm{j}) \wedge \exists(\mathrm{x})($ ganhou $(\mathrm{x}))]$}

Agora, mais uma vez, estamos diante de uma negação de escopo amplo, portanto, pouco informativa, o que aciona um processo pragmático de especificação de escopo. Mais uma vez, só faz sentido, do ponto de vista pragmático, considerar que a negação opera apenas sobre o primeiro conjunto, uma vez que a negação dos dois conjuntos seria uma redundância (violando a máxima da brevidade) e a negação exclusiva do segundo conjunto (ou seja, a consideração e que ninguém ganhou a corrida) geraria uma contradição (violando a máxima da qualidade).

O que a abordagem aqui exposta assume, portanto, é que, no nível semântico de análise, uma sentença qualquer seja representada pela apresentação formal de seus acarretamentos lexicais, não havendo, portanto, a necessidade de supor qualquer escala. Assume ainda que, semanticamente, a negação sentencial é de escopo amplo, e que a especificação de escopo ocorre apenas no módulo pragmático de interpretação, em nome da necessidade de tornar o enunciado mais informativo. Evidentemente, essa solução sobrecarrega a representação semântica com uma formalização que, a rigor, deve dar expressão aos acarretamentos decorrentes da presença dos itens lexicais presentes na sentença proferida. Uma representação semântica capaz de fundamentar o conjunto de inferências que se costuma supor a partir do proferimento de (52) seria (57).

$$
\neg[\operatorname{ganhou}(\mathrm{j}) \wedge \operatorname{participou}(\mathrm{j}) \wedge \exists(\mathrm{x}) \operatorname{ganhou}(\mathrm{x})]
$$

20 A representação (56) não é uma representação alternativa a (53) para (52). Tanto (56) quanto (53) são, na verdade, representações semânticas parciais de (52), aquelas necessárias para computar as inferências relevantes para a análise. 
M. Goldnadel Duas soluções conversacionais para a descrição de inferências pressuposicionais em enunciados de sentenças negativas e condicionais com o gatilho ganhar

Uma tal solução, apesar de contar com uma certa sobrecarga representacional, livra-se de uma série de suposições indesejáveis encontradas na proposta de Romoli: não precisa estipular qualquer tipo de filtro sobre alternativas, não precisa estipular um operador sintático com função essencialmente pragmática e não precisa admitir qualquer assimetria em escalas de quantidade motivadas pelos tradicionais gatilhos pressuposicionais.

É importante ainda registrar que, por ser resultado de uma especificação pragmática de escopo, a inferência (54) pode ser desfeita em contextos específicos, como quando a leitura derivada produz uma contradição com algum outro conteúdo expresso, conforme se observa em (58).

(58) João não ganhou a corrida, porque não participou.

Uma interpretação on line de (58) produziria primeiramente a inferência $(54)^{21}$, que, em seguida, entraria em contradição com a proposição expressa pela oração causal, provocando uma reinterpretação. O processo completo aparece em (59).

(59a) $\neg[$ ganhou $(j) \wedge$ participou $(j)]$

(59b) $\neg$ ganhou $(j) \wedge$ participou(j) (especificação de escopo de (59a) por respeito às máximas $\mathrm{da}$ qualidade $\mathrm{e} \mathrm{da}$ brevidade)

(59c) $\neg$ participou $(\mathrm{j})$ (conteúdo da oração causal)

(59d) $\neg$ ganhou(j) (acarretamento de (59c)

(59e) $\neg$ ganhou(j) $\neg \neg$ participou(j) (acarretamento de (59c) e (59d), que anula a inferência (59b))

O resultado em (59e), assim como o resultado intermediário em (59b), é compatível com a representação semântica (53) - a mesma que aparece em (59a) -, em que a negação tem escopo amplo. A descrição proposta lida de um modo bastante simples com a projeção de conteúdos sob o escopo do operador de negação, mantendo-se dentro dos princípios griceanos, sem precisar apelar para estipulações que acarretem qualquer tipo de intrusão da pragmática sobre a sintaxe.

\subsection{Inferências em sentenças condicionais}

Para descrever a projeção de pressuposições em sentenças condicionais de acordo com o novo modelo de análise, é necessário considerar que, a par do aparato tradicional para formular representações semânticas, é necessário um aparato descritivo pragmático para formular representações pragmáticas.

Revista Letras, 21 Daí a sensação de garden pathing.

Curitiba, UFPR, n. 96, pp.74-103, jul./dez. 2017. ISSN 2236-0999 (versão eletrônica) 
As representações pragmáticas aqui são realizadas com o recurso de operadores epistêmicos de crença. Sendo assim, uma simples sentença como como (60) recebe a representação semântica (61) e a representação pragmática (62).

(60) Jane ganhou a corrida.

(61) $\operatorname{ganhou}(\mathrm{j})$

(62) $\mathrm{B}_{\mathrm{f}}[\operatorname{ganhou}(\mathrm{j})]^{22} \quad$ (O falante acredita que Jane ganhou a corrida)

Esse tipo de representação pragmática poderia ter sido utilizado na seção anterior, mas foi omitido para simplificar a exposição. A descrição da projeção de pressuposições em sentenças condicionais, no entanto, não pode abrir mão desse recurso. Vamos começar a análise da sentença (63).

(63) Se Jane ganhou, ela está celebrando agora.

As representações semântica e pragmática de (63) são apresentadas em (64) e (65), respectivamente.

(64) $\operatorname{ganhou}(\mathrm{j}) \rightarrow \operatorname{celeb}(\mathrm{j})$

(65) $\quad \mathrm{B}_{\mathrm{f}}[\operatorname{ganhou}(\mathrm{j}) \rightarrow \operatorname{celeb}(\mathrm{j})]$

Assim como o falante, ao proferir (63), está no estado epistêmico (65), também estará nos estado epistêmico (67) por conhecer a semântica de ganhar, em (66).

(66) $[[$ ganhar $]]=\lambda x[\operatorname{ganhar}(\mathrm{x}) \wedge \operatorname{participar}(\mathrm{x})]$

(67) $\mathrm{B}_{\mathrm{f}}[\operatorname{ganhou}(\mathrm{j}) \rightarrow \operatorname{participar}(\mathrm{j})]^{23}$

Adicionalmente, um falante que tenha proferido (63) estará nos estados epistêmicos apresentados em (68) e (69) (Cf. GAZDAR, 1979).

(68a) $\neg \mathrm{B}_{\mathrm{f}}$ [ganhou(j)] (O falante não acredita que Jane ganhou.)

(68b) $\neg \mathrm{B}_{\mathrm{f}} \neg[$ ganhou(j)] (O falante não acredita que Jane não ganhou.)

(69a) $\neg \mathrm{B}_{\mathrm{f}}[\mathrm{celeb}(\mathrm{j})] \quad$ (O falante não acredita que Jane celebrou.)

(69b) $\neg \mathrm{B}_{\mathrm{f}} \neg[\operatorname{celeb}(\mathrm{j})] \quad$ (O falante não acredita que Jane não celebrou.)

22 O operador intensional $B$, com o subscrito $f$ para indicar que se trata de estado de crença do falante, expressa a ideia de que, para o enunciador, não existe mundo possível em que o conteúdo sobre o qual B tem escopo seja falso.

23 O que a representação em (67) expressa é o fato de que, por conhecer a semântica de ganhar, ou seja, por saber que a verdade de uma sentença proferida contendo o item lexical ganhar acarreta um evento de participação, todo o falante que acreditar que Jane ganhou a corrida acreditará, necessariamente, que Jane participou da corrida. 
M. Goldnadel Duas soluções conversacionais para a descrição de inferências pressuposicionais em enunciados de sentenças negativas e condicionais com o gatilho ganhar

É importante identificar as fontes dos estados epistêmicos (67), (68) e (69). Enquanto (67) decorre de conhecimento semântico, (68) e (69) decorrem de inferências conversacionais relacionadas ao uso de sentenças condicionais.

Tanto o estado epistêmico em (67) quanto os estados epistêmicos em (68) e (69) caracterizam-se por uma considerável estabilidade. O estado (67), como se disse, decorre de conhecimento semântico, de modo que um falante que admita uma vitória sem uma participação não compreendeu ainda o significado de ganhar (poderia ser o caso de um aprendiz da língua, por exemplo). Do mesmo modo, deve-se supor nos estados epistêmicos em (68) e (69) todo falante que realize o proferimento de (63). Se esse falante acreditasse na verdade do antecedente, teria sido mais informativo, em virtude das condições-de-verdade de condicionais, se tivesse proferido a conjunção das duas proposições atômicas - por isso, a suposição de (68a) como um estado epistêmico do falante. Se acreditasse na falsidade do antecedente, precisaria, em virtude das condições-de-verdade de condicionais, acreditar na falsidade do consequente, de modo que seria mais informativo se se expressasse com a conjunção da negação das duas proposições atômicas que compõem o condicional - por isso, a suposição de (68b) como um estado epistêmico do falante. Se acreditasse na verdade do consequente, não precisaria condicioná-lo à verdade do antecedente, sendo mais informativo se o proferisse isoladamente - por isso, a suposição de (69a) como um estado epistêmico do falante. Se acreditasse na falsidade do consequente, mais uma vez em virtude das condições-de-verdade de condicionais, precisaria acreditar na falsidade do antecedente, caso em que seria mais informativo, novamente, se se expressasse com a conjunção da negação das duas proposições atômicas que compõem o condicional - por isso, a suposição de (69b) como um estado epistêmico do falante.

Em suma, a crença do falante em (67), derivada de seu conhecimento semântico, e as inferências pragmáticas resultantes do uso de sentenças condicionais, expressas em (68) e (69), constituem balizas bastante sólidas para qualquer inferência subsequente. Mais do que isso, juntos, esses estados epistêmicos impedem a geração de determinadas suposições. Imagine-se, por exemplo, um interlocutor que, ao ouvir (63) arriscasse supor que Jane não participou da corrida, tentando colocar-se no estado epistêmico (70).

$$
\mathrm{B}_{\mathrm{f}} \neg[\operatorname{participou}(\mathrm{j})]
$$

O estado epistêmico (70), combinado com o estado (67) - que vimos ser inegociável, já que resulta de conhecimento semântico -, acarreta que o falante esteja no estado epistêmico (71).

$$
\mathrm{B}_{\mathrm{f}} \neg[\operatorname{ganhou}(\mathrm{j})]
$$

Revista Letras, Curitiba, UFPR, n. 96 , pp.74-103, jul./dez. 2017. ISSN 2236-0999 (versão eletrônica) 
O problema é que (71) é uma contradição com (68b), um dos estados epistêmicos disparados pelo uso da sentença condicional. Aqui, portanto, aquele que ouve (63) e que, por isso, dada a lógica conversacional que opera sobre sentenças condicionais, deriva automaticamente as inferências em (68)e (69), encontra-se impossibilitado de considerar que o falante se encontre no estado (70). O fato é que (70) produz, ao fim e ao cabo, uma contradição com uma das implicaturas de quantidade escalares. A única saída, então, é rejeitar (70), como em (72).

$$
\neg \mathrm{B}_{\mathrm{f}} \neg[\operatorname{participou}(\mathrm{j})]
$$

O que o modelo de análise aqui proposto, que usa apenas recursos inferenciais (e nenhuma estipulação pragmática ${ }^{24}$ ) propõe, portanto, é que (72) é a inferência decorrente de (63). Essa inferência, no entanto, apesar de resultado de considerações de caráter conversacional, não é uma implicatura; ela é apenas uma inferência necessária, dada a semântica de ganhar e a lógica conversacional que produz implicaturas de quantidade escalares a partir do uso de sentenças condicionais.

Embora (72) não seja ainda a inferência desejada - já que a pressuposição associada a (63) costuma ser $\mathrm{B}_{\mathrm{f}}[$ participou(j) - está muito próxima de derivar, a partir de inferência pragmática, o que normalmente se considera a pressuposição desse enunciado. De fato, basta considerar opinativo o enunciador de (63) em relação à participação de Jane na disputa aludida, como em (73), para que a pressuposição (74) seja a conclusão lógica do silogismo disjuntivo formado por essa premissa e pela inferência (72).

(73) $\quad \mathrm{B}_{\mathrm{f}}[$ participou $(\mathrm{j})] \vee \mathrm{B}_{\mathrm{f}} \neg[$ participou(j) $]$ (Estado epistêmico de um falante opinativo)

(72) $\neg \mathrm{B}_{\mathrm{f}} \neg[$ participou $(\mathrm{j})]$

(74) $\quad B_{f}[\operatorname{participou}(j)]$

De acordo com essa descrição, portanto, a inferência mais elementar a partir de um enunciado como (63) é a representada por (72). Essa inferência resulta reforçada apenas depois da consideração de que o enunciador do condicional é opinativo, o que implica considerá-lo no estado epistêmico $(73)^{25}$.

O modelo proposto apresenta algumas vantagens em relação ao encontrado em Romoli (2015). Do ponto de vista explanatório, não precisa supor escalas de quantidade assimétricas para pressuposições (que impedem, por estipulação ad hoc, a geração de certas inferências). Adicionalmente, livra-se da necessidade de estipular um operador de exaustividade sintático, cujo estatuto soa como altamente duvidoso, uma vez que conta, para a sua ação, com o output de 24 A única estipulação aqui realizada é semântica, a de que ganhar acarreta participar.

25 O recurso à consideração de falantes opinativos para a geração de inferências pragmáticas também pode ser encontrado em Soames (1982) e Sauerland (2004). 
M. Goldnadel Duas soluções conversacionais para a descrição de inferências pressuposicionais em enunciados de sentenças negativas e condicionais com o gatilho ganhar

processos eminentemente pragmáticos (como o cálculo das alternativas passiveis de exclusão). Um tal modelo supõe um grau de intrusão da pragmática jamais visto, já que se trata de uma intrusão em processos sintáticos.

Do ponto de vista descritivo, o novo modelo proposto apresenta duas vantagens. A primeira é a de que não gera, como em Romoli (2015), o problema da provisoriedade. Como a geração de implicaturas de quantidade em consequentes de condicionais é exatamente igual à de antecedentes, o cálculo proposto é o mesmo para enunciados condicionais em que o gatilho figura no consequente. Nesse sentido, a cobertura descritiva ainda é maior.

Uma segunda vantagem descritiva é a possibilidade de descrever o que corre em contextos de ignorância explícita com bastante naturalidade. Para entender como, é preciso considerar, com Gazdar (1979), que enunciados com modais de possibilidade disparam implicatura de quantidade oracionais similares às disparadas por sentenças condicionais. Uma sentença como (75), por exemplo, gera as implicaturas em $(76)^{26}$.

(75) Talvez ele tenha ganhado uma competição.

(76a) $\neg \mathrm{B}_{\mathrm{f}}$ [ganhou(ele)]

(76b) $\neg \mathrm{B}_{\mathrm{f}} \neg[$ ganhou(ele)]

Aqui, mais uma vez, não é possível considerar que o falante esteja em um estado epistêmico como (77).

(77) $\quad \mathrm{B}_{\mathrm{f}} \neg[$ participou(ele)]

O problema é que (77), combinado (78), que decorre do conhecimento semântico do falante, produz o estado epistêmico (79), que entra em conflito (76b).

(78) $\quad \mathrm{B}_{\mathrm{f}}$ [ganhou(ele) $\rightarrow$ participar(ele)]

(79) $\quad \mathrm{B}_{\mathrm{f}} \neg[$ ganhou(ele) $]$

Diante dessa contradição, o ouvinte precisa supor que o falante esteja no estado epistêmico (80) - o estado contraditório com (77).

(80) $\neg \mathrm{B}_{\mathrm{f}} \neg[$ participou(ele) $]$

Mas agora (80) é justamente a inferência que se precisa alcançar para descrever adequadamente um caso típico de suspensão de pressuposição em um contexto de ignorância explícita como o que vê em (81).

Revista Letras, 26 Para simplificar a representação, ele está sendo formalizado como um nome próprio.

Curitiba, UFPR, n. 96, pp. $74-103$, jul./dez. 2017. ISSN 2236-0999 (versão eletrônica) 
(81) [Contexto: Os interlocutores ligam a televisão e veem um atleta conhecido em uma entrevista, visivelmente feliz.]

A: Por que será que ele está tão feliz?

B: Talvez ele tenha ganhado uma competição.

Neste caso, é evidente que o enunciado não pressupõe a participação recente do atleta em uma competição. E nem poderia, já que não se pode supor um falante opinativo num caso como este. Sendo assim, não ocorre o silogismo disjuntivo normalmente responsável pela geração da inferência tradicionalmente chamada de pressuposição. O máximo que se pode concluir é que o falante esteja no estado (80) e, provavelmente, também no estado (82).

(82) $\neg \mathrm{B}_{\mathrm{f}}[$ participou(ele) $]$

Os estados (80) e (82) acarretam o estado (83), que expressa a situação de um falante agnóstico quanto ao conteúdo normalmente considerado pressuposto, justamente o estado contraditório de um falante opinativo.

(83) $\neg \mathrm{B}_{\mathrm{f}}[\operatorname{participou}($ ele $)] \wedge \neg \mathrm{B}_{\mathrm{f}} \neg[$ participou(ele) $]$

A descrição proposta, portanto, lida de modo bastante natural com a ausência da inferência tradicionalmente chamada de pressuposição em contextos de ignorância explícita.

\section{Considerações finais}

Pressuposições continuam sendo um tema desafiador, tanto no que diz respeito à compreensão de sua natureza quanto no que diz respeito à forma adequada de descrição das inferências associadas aos itens lexicais tradicionalmente chamados de gatilhos. Desde o início do século, uma nova onda de trabalhos acadêmicos tem se caracterizado por uma guinada conversacional no tratamento de pressuposições. Nesse movimento, uma série de gatilhos leves, caracterizados por sua maior cancelabilidade ${ }^{27}$, têm sido analisados por alguns autores como itens lexicais responsáveis pela ativação de alternativas semelhantes àquelas responsáveis pela geração de implicaturas de quantidade escalares.

Entre essas teorias, as de maior circulação, produzidas por pesquisadores com grande dedicação ao tema, embora realizem um esforço considerável para situar a explicação e a descrição de pressuposições no âmbito de uma pragmática

27 Os gatilhos leves se diferenciam dos pesados ainda no que diz respeito às inferências que produzem em sentenças quantificadas. 
M. Goldnadel Duas soluções conversacionais para a descrição de inferências pressuposicionais em enunciados de sentenças negativas e condicionais com o gatilho ganhar conversacional, ainda retêm um resíduo convencionalista, que aparece ora na estipulação de alternativas escalares $a d h o c^{28}$, ora na determinação, também ad $h o c$, de quais escalas podem e quais não podem ser consideradas operantes, ora na suposição difícil de defender de uma intrusão de mecanismos de natureza fundamentalmente pragmática na Sintaxe. Como todas as demais, essas teorias seguem no esforço de propor modelos preditivos, capazes de descrever de modo adequado as inferências intuitivamente realizadas pelos falantes.

Este artigo procurou apresentar uma alternativa conversacional para a explicação da natureza e a descrição do modo como são derivadas inferências tradicionalmente vistas como pressuposições. Do ponto de vista explanatório, o modelo proposto considera as inferências associadas aos tradicionais gatilhos como resultado não de qualquer tipo de marcação convencional no âmbito da Pragmática, mas como consequência da semântica dos gatilhos e da consideração de estados epistêmicos decorrentes desse tipo de conhecimento semântico, bem como de estados epistêmicos inferidos a partir dos conteúdos de enunciados, resultado da consideração das tradicionais máximas conversacionais. Tudo isso como parte de um processo mais amplo, comprometido com a estratégia mais geral, certamente assumida por todos os falantes, de evitar comportamentos linguísticos contraditórios. Do ponto de vista descritivo, o modelo proposto tem sucesso na predição de um conjunto significativo de inferências pragmáticas, inclusive algumas produzidas em contextos normalmente problemáticos para as alternativas descritivas correntes.

As duas soluções aqui apresentadas, embora tenham sido ilustradas a partir da consideração de apenas um tipo de gatilho, podem ser estendidas ao tratamento de outros tipos de gatilho leve. Romoli (2015), por exemplo, defende a aplicabilidade de sua solução à descrição da produção de inferências pressuposicionais em enunciados com verbos aspectuais e verbos epistêmicos. O segundo modelo apresentado também pode ser aplicado, em linhas gerais, à descrição de inferências associadas a outros tipos de gatilhos. Entretanto, dada a dependência deste modelo da consideração da semântica particular de cada gatilho, eventuais ajustes, possivelmente a partir da consideração de outros determinantes de natureza semântica e pragmática mais geral, podem ser necessários.

28 Como é o caso de Chemla (2009).
Revista Letras, Curitiba, UFPR, n. 96, pp.74-103, jul./dez. 2017. ISSN 2236-0999 (versão eletrônica) 


\section{Referências Bibliográficas}

ABUSCH, Dorit. Lexical Alternatives as a Source of Pragmatic Presuppositions. In: SALT XII, 2002, SALT XII Proceedings, Ithaca, 2002, p. 1-19.

ABRUSÁN, Márta. Predicting the presuppositions of soft triggers. Linguistics and Philosophy, n. 34, p. 491-535, 2011.

CARSTON, Robyn. Negation, Presupposition and the Semantics/Pragmatics Distinction. Journal of Linguistics, v. 34, n. 2, p. 309-350, set. 1998.

CHEMLA, Emmanuel. Projecting Presuppositions with Scalar Implicatures. In: SuB12, 2009, Oslo, Proceedings of SuB12. Oslo: University of Oslo, 2008, p. 8191.

Similarity: towards a unified account of scalar implicatures, free choice permission and presupposition projection, 2009. Submetido a Semantics and Pragmatics.

CHIERCHIA, Gennaro; MCCONNELL-GINET, Sally. Meaning and grammar. Massachussets: MIT, 1990.

CHIERCHIA, Gennaro; FOX, Danny; SPECTOR, Benjamin. The grammatical view of scalar implicatures and the relationship between semantics and pragmatics. In: MAIENBORN, C.; VON HEUSINGER, K.; PORTNER, P. Semantics: An International Handbook of Natural Language Meaning, vol. 3. Berlin: Mouton de Gruyter, 2012.

102 FOX, Danny. Free Choice and the Theory of Scalar Implicatures. In: SAUERLAND, Uli;

STATEVA, Penka. Presupposition and Implicature in Compositional Semantics. New York: Palgrave Macmillan, 2007.

GAZDAR, Gerald. Pragmatics: Implicature, preesuposition and logical form. New York: Academic Press, 1979.

GEURTS, Bart. Presuppositions and pronouns. Amsterdan: Elsevier, 1999.

GRICE, Herbert Paul. Further notes on logic and conversation. In: Studies in the way of words. Harvard: Harvard University Press, 1989. p. 41-57.

HEIM, Irene. On the projection problem for presuppositions. In: PORTNER, Paul; PARTEE, Barbara Hall. Formal Semantics: the essential readings. Oxford: Blackwell, 2002 [1983]. p. 249-260.

KADMON, Nirit. Formal Pragmatics: Semantics, Pragmatics, Presuppositions, and Focus. Oxford: Blackwell, 2001. 
M. Goldnadel Duas soluções conversacionais para a descrição de inferências pressuposicionais em enunciados de sentenças negativas e condicionais com o gatilho ganhar
KARTTUNEN, Lauri. Presuppositions of compound sentences. Linguistic Inquiry, v. 4, n. 2, p. 169-193.

Pressupposition and linguistic context. In: DAVIS, Steven. Pragmatics: a reader. Oxford: Oxford University Press, 1991 [1974], p. 406-415.

KARTTUNEN, LAURI, PETERS, STANLEY. Conventional implicature. In: OH, Choon-kyu, DINNEEN, David A. Syntax and Semantics. New York: Academic, 1979, v. 11, p. 1-56.

OLIVEIRA, Tamara Melo de. Convenção ou conversação: evidências para a determinação da natureza do fenômeno pressuposicional. 124 f. Dissertação (Mestrado em Linguística) - Universidade Federal do Rio Grande do Sul, Porto Alegre, 2015.

ROMOLI, Jacopo. The Presuppositions of Soft Triggers are not Presuppositions. In: SALT 21, 2011, New Brunswick, Proceedings of SALT 21, New Brunswick: Rutgers University, 2011, p. 1-15.

. Soft but Strong: Neg-raising, Soft triggers, and Exhaustification. 267 f. Tese - Harvard University, 2012.

The Presuppositions of Soft Triggers are Obligatory Scalar Implicatures. Journal of Semantics, v. 32, p. 173-219, 2015.

SIMONS, Mandy. On the conversational basis of some presuppositions. In: CAPONE, Alessandro; LO PIPARO, Franco; CARAPEZZA, Marco. Perspectives on Linguistic Pragmatics. Londres: Springer, 2013 [2001]. p. 329-348.

SAUERLAND, Uli. On embedded implicatures. Journal of Cognitive Science 5, p. 104-137.

SOAMES, Scott. A projection problem for speaker presuppositions. Linguistic Inquiry. v. 10, n. 4, p. 623-666, 1979.

. How pressupositions are inherited: a solution to the projection problem. In: DAVIS, Steven. Pragmatics: a reader. Oxford: Oxford, 1991 [1982], p. $428-470$.

STALNAKER, Robert C. Pragmatic pressupositions. In: DAVIS, Stephen (Ed.). Pragmatics: a reader. Oxford: Oxford University, 1991, p. 471-481

VAN DER SANDT, Rob A. Presupposition Projection as Anaphora Resolution. Journal of Semantics, v.9, n. 4, 1992. p. 333-377.

Submetido: 01/02/2017

Aceito: 30/06/2017
Revista Letras, Curitiba, UFPR, n. 96, pp.74-103, jul./dez. 2017. ISSN 2236-0999 (versão eletrônica) 